SAND95 - 1609

Unlimited Release

Printed March 1996
Distribution

Category UC-903

\title{
Application of Non-Intrusive Geophysical Techniques at the Mixed Waste Landfill, Technical Area 3, Sandia National Laboratories, New Mexico
}

\author{
Jerry L. Peace \\ Environmental Restoration Project \\ Sandia National Laboratories \\ Albuquerque, NM 87185-5800 \\ David A. Hyndman \\ Sunbelt Geophysics \\ P.O. Box 36404 \\ Albuquerque, NM 87176 \\ Tim J. Goering \\ Gram, Inc. \\ 8500 Menaul Blvd. NE, Suite B-370 \\ Albuquerque, NM 87112
}

\begin{abstract}
The Environmental Restoration Project at Sandia National Laboratories, New Mexico is tasked with assessment and remediation of the Mixed Waste Landfill in Technical Area 3. The Mixed Waste Landfill is an inactive radioactive and mixed waste disposal site. The landfill contains disposal pits and trenches of questionable location and dimension. Non-intrusive geophysical techniques were utilized to provide an effective means of determining the location and dimension of suspected waste disposal trenches before Resource Conservation and Recovery Act intrusive assessment activities were initiated. Geophysical instruments selected for this investigation included a Geonics EM-31 ground conductivity meter, the new Geonics EM-61 high precision, time-domain metal detector, and a Geometrics 856 total field magnetometer. The results of these non-intrusive geophysical techniques were evaluated to enhance the efficiency and cost-effectiveness of future waste-site investigations at Environmental Restoration Project sites.
\end{abstract}





\section{ACKNOWLEDGMENT}

The authors wish to thank Hans Oldewage and Gordon Coulter of Department 7714, . Radiation Protection Operations, for their valuable support during this investigation. 



\section{CONTENTS}

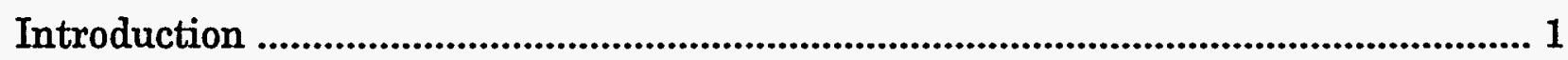

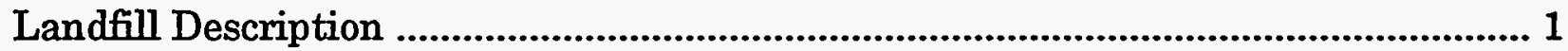

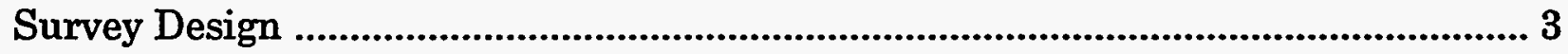

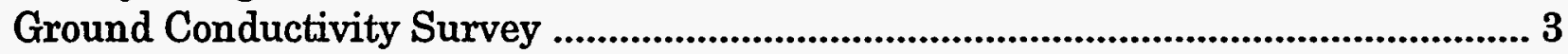

Magnetic Gradient Survey ............................................................................................. 6

Metal Detection Survey ..................................................................................................... 6

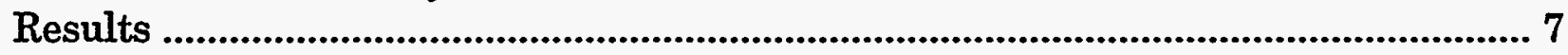

Ground Conductivity ......................................................................................... 7

Magnetic Gradient ............................................................................................................ 10

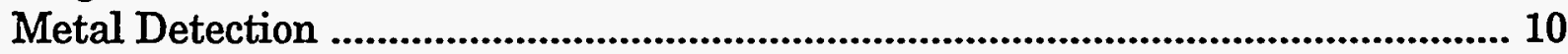

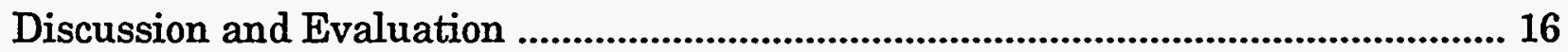

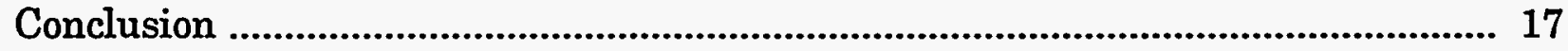

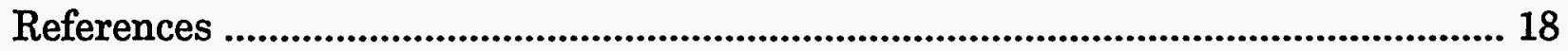

\section{Figures}



2 Mixed Waste Landfill Engineering Design Map 91342 ..................................... 4

3 Mixed Waste Landfill Geophysical Survey Grid .................................................... 5

4 Mixed Waste Landfill EM-31 Conductivity .............................................................. 8

5 Mixed Waste Landfill EM-31 In-Phase Response .............................................. 9

6 Mixed Waste Landfill Total Magnetic Field - Top Sensor ................................. 11

7 Mixed Waste Landfill Total Magnetic Field - Bottom Sensor ............................ 12

8 Mixed Waste Landfill Magnetic Gradiant ............................................................. 13

9 Mixed Waste Landfill Superposition of Magnetic Gradient

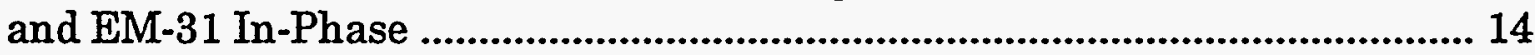

10 Mixed Waste Landfill EM-61 Response .............................................................. 15 


\section{Application of Non-Intrusive Geophysical Techniques \\ at the Mixed Waste Landfill, Technical Area 3, Sandia National Laboratories, New Mexico}

\section{Introduction}

The Environmental Restoration (ER) Project at Sandia National Laboratories, New Mexico (SNL,NM) is tasked with assessment and remediation of the Mixed Waste Landfill (MWL) in Technical Area 3 under the SNL,NM Resource Conservation and Recovery Act (RCRA) HSWA Part B Operating Permit. The MWL was established in 1959 as a disposal site for radioactive and mixed wastes. The 2.6 acre compound consists of two distinct disposal areas, classified and unclassified (Figure 1). The classified area, 0.6 acres in size, contains up to 40 disposal pits. The unclassified area, 2.0.acres in size, reportedly contains 7 disposal trenches. The exact location and dimension of individual pits and trenches is unknown except for SNL,NM MWL engineering design maps. These design maps are not believed to represent the "as built" configuration of the landfill. Therefore, verification of pit and trench location and dimension was necessary before RCRA-driven intrusive assessment activities could be initiated.

Disposal trenches in the northern half of the unclassified area of the MWL were selected for this investigation. Historical records indicate that 4 disposal trenches were excavated in this area. Non-intrusive geophysical surveys were conducted to determine the location and dimension of the reported disposal trenches, and to evaluate the effectiveness of each technique. Three different geophysical instruments were selected for this investigation. A Geonics EM-31 ground conductivity meter was used to obtain ground conductivity information. A new instrument, the Geonics EM-61 high resolution metal detector, was used to locate and map buried metal. A Geometrics G-856AX proton precession magnetometer, operated in the gradient mode, was used to obtain vertical magnetic gradient information. This report documents the acquisition and interpretation of the geophysical field data and evaluates the efficiency and cost-effectiveness of the surveys.

\section{Landfill Description}

Trenches in the northern half of the unclassified area of the MWL were excavated with bulldozers to reported depths of 15 to 20 feet, widths of 20 to 35 feet, and lengths of 150 to 180 feet. The trenches were excavated in unconsolidated alluvial sands and gravels. Wastes in the trenches are reported to include construction and demolition materials, contaminated equipment and soils, lead shielding, wood crates, steel drums, cardboard boxes, and dry solids. Wastes were disposed of at random 






with no regard to waste source or type. Each trench was reportedly backfilled with soil on a quarterly basis and eventually bermed with originally excavated soils.

Engineering design map 91342 shows the location of 4 trenches, A, B, C, and D, in the northern half of the unclassified area of the MWL (Figure 2). The design map indicates trenches of equal length, width, depth, and spacing on the 1 acre site. Field observation, however, did not support the designed configuration. There are 3 earthen berms at the site, presumably indicating three trenches, each of different length, width, and spacing. The north and south ends of each earthen berm is marked with a steel fence post.

\section{Survey Design}

The northern half of the unclassified area covers approximately $43,000 \mathrm{ft}^{2}\left(3995 \mathrm{~m}^{2}\right)$ and is fenced on all four sides. The area was grided on $\mathbf{5}$ foot centers starting with the northwest corner of the landfill (Figure 3 ). The northwest cornerpost was designated as the origin, $(0,0)$, with 5 foot stations staked to the east along the north fenceline as $5 \mathrm{E}, 10 \mathrm{E}, 15 \mathrm{E}, \ldots$ to $200 \mathrm{E}$ and south along the west fenceline as $5 \mathrm{~S}, 10 \mathrm{~S}$, $15 \mathrm{~S}, \ldots$ to $215 \mathrm{~S}$. Establishing this grid required approximately 3 hours with a 2-man crew.

Each 5 foot grid station was occupied for data acquisition with the EM-31 and the total field magnetometer. Readings were taken from west to east then east to west along successive survey lines with spatial control maintained within 0.5 feet. The EM-61 is a wheel-mounted instrument with an encoder that automatically triggers data acquisition during a traverse. The EM-61 was pulled along each grid line with data acquired every 8 inches $(20 \mathrm{~cm})$. All data were recorded in the field with data loggers.

The north, south, and west fences consist of 3-foot high woven wire on metal posts. The east fence is 6-foot high chain link on metal posts. Six steel fence posts were the only surface obstructions encountered in the survey area. These posts mark the ends of each of the 3 observed earthen berms. One pair is located at $15 \mathrm{~S}, 15 \mathrm{E}$ and $200 \mathrm{~S}, 17 \mathrm{E}$; a second pair at $40 \mathrm{~S}, 100 \mathrm{E}$ and $193 \mathrm{~S}, 100 \mathrm{E}$; and a third pair at $30 \mathrm{~S}, 155 \mathrm{E}$ and $190 \mathrm{~S}, 162 \mathrm{E}$.

\section{Ground Conductivity Survey}

The Geonics EM-31 was operated in the vertical dipole mode and both ground conductivity and the in-phase component of the induced magnetic field were recorded. The in-phase component, measured in parts per thousand (ppt) of the primary magnetic field, is responsive to highly conductive objects such as buried 



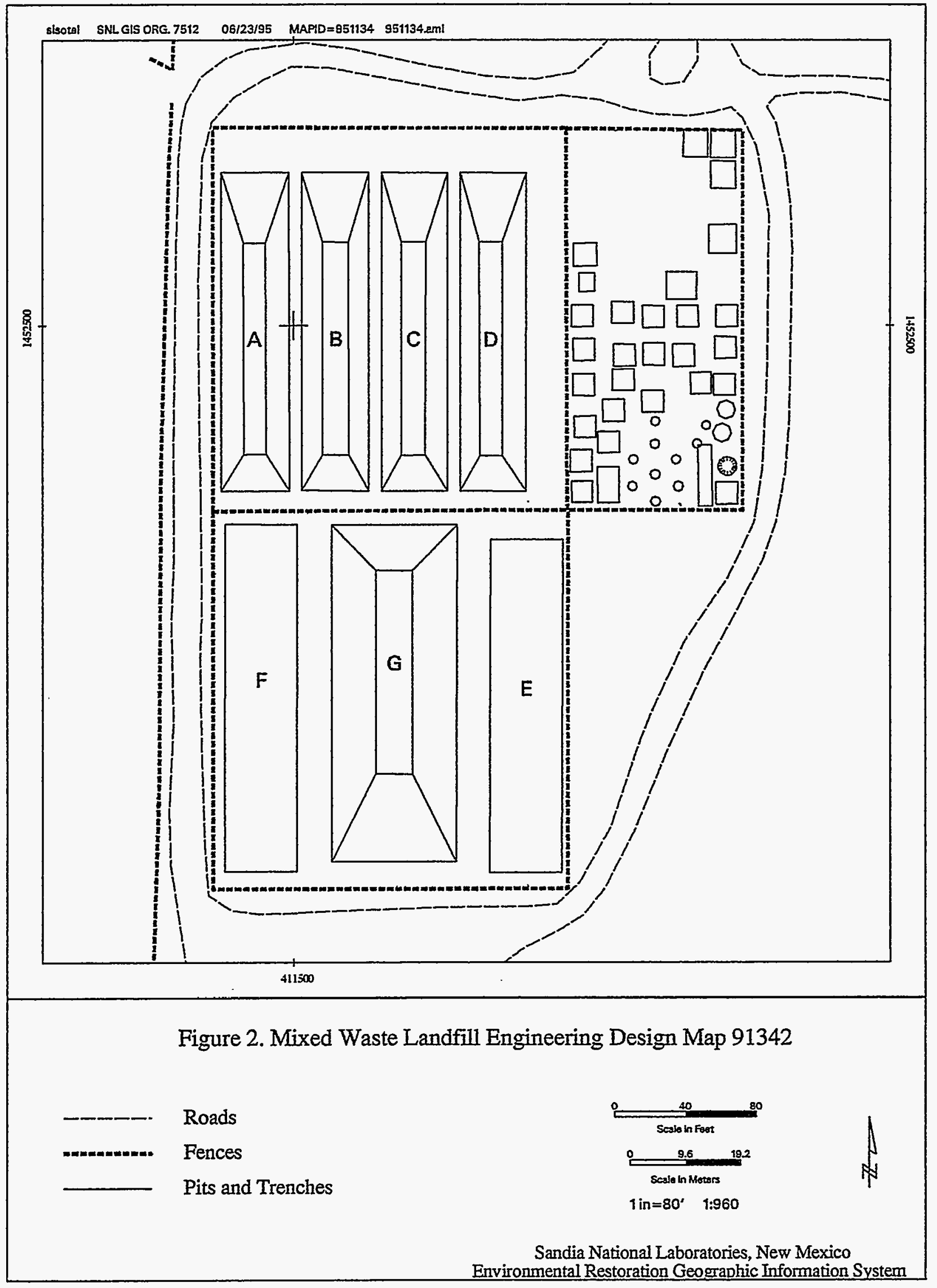




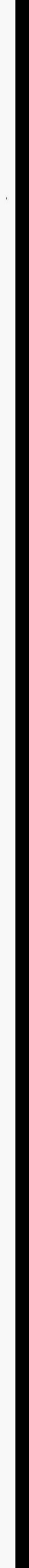




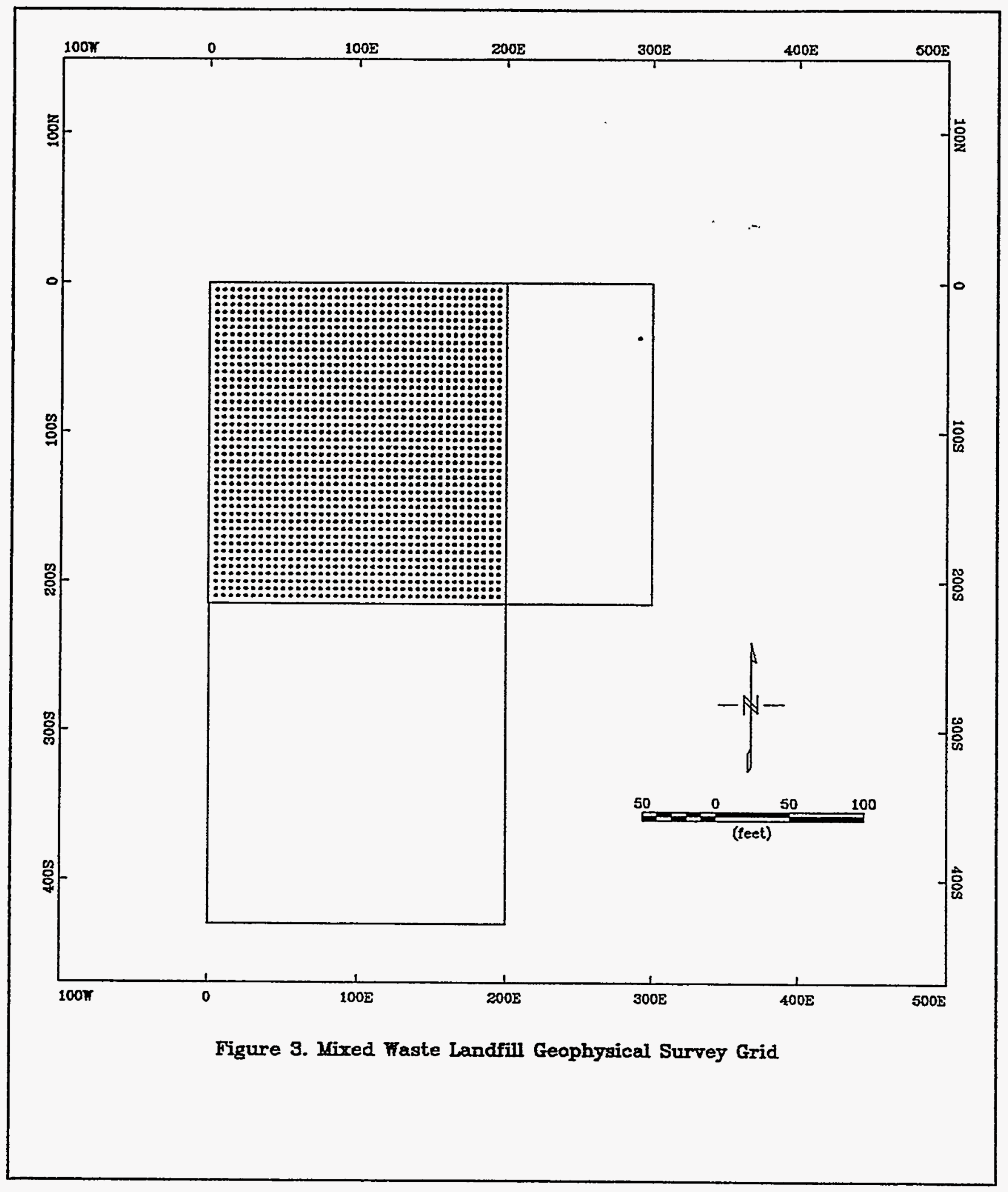


drums and other ferrous and non-ferrous materials. Ground conductivity, measured in milliSiemens per meter $(\mathrm{mS} / \mathrm{m})$, provides information about subsurface moisture and porosity. The EM-31 has an effective depth of penetration of approximately 18 feet $(6 \mathrm{~m})$. Data collection required approximately 7 hours. EM-31 ground conductivity and in-phase field data were processed with DAT31 (Geonics, 1992) and compiled and plotted with Geosoft Mapping and Processing System (GMPS), a PCbased mapping and processing software package (Geosoft, 1994).

\section{Magnetic Gradient Survey}

A Geometrics G-856AX proton precession magnetometer operated in the gradient mode was used to acquire vertical magnetic gradient data. Vertical magnetic gradient measurements have several advantages over conventional total field magnetic measurements. Near-surface sources (ferrous objects) are accentuated preferentially over deeper regional sources, providing far superior resolving power. The data is much cleaner because the regional gradient has been suppressed, and because time-varying magnetic storm activity and diurnal variations are automatically removed.

The vertical magnetic gradient survey utilized two magnetic sensors deployed on the same vertical staff. The top and bottom sensors were positioned 9.2 feet $(2.8 \mathrm{~m})$ and 4.6 feet $(1.4 \mathrm{~m})$ above the ground, respectively. The vertical magnetic gradient was calculated by subtracting the top sensor reading from the bottom sensor reading, then dividing by the sensor separation. Vertical magnetic gradient data collection required approximately 8.5 hours. The gradient data were reduced using MAGLOC (TerraSense, 1993) and compiled and plotted with GMPS.

The diurnal drift in the magnetic field was estimated by reoccupying selected data stations. Both top and bottom sensor data were corrected for drift. Drift during this survey was found to be less than 25 gamma; insignificant when compared to observed magnetic anomalies of several hundred gamma.

\section{Metal Detection Survey}

The Geonics EM-61 was utilized to discriminate between soil conductivity and highly conductive ferrous and non-ferrous metallic objects. The EM-61 is an extremely sensitive metal detector which measures the time-rate of decay of the induced magnetic field. The response from buried metal, measured in millivolts $(\mathrm{mV})$, is measured during off-times between electromagnetic pulses. The EM-61 has an effective depth of penetration of approximately $10 \mathrm{feet}(3 \mathrm{~m})$. Data collection required approximately 4 hours. EM-61 response data were processed with DAT61 (Geonics, 1994) and compiled and plotted with GMPS. 



\section{Results}

\section{EM-31 Ground Conductivity Survey}

The EM-31 is designed to measure subtle changes in soil conductivity generated by lateral contrasts in soil moisture content, soil compaction, and soil mineral content. Large fluctuations in instrument response occur when the EM-31 is operated near concentrations of surface or subsurface metal. This instrument response to metal is well beyond the designed operational parameters of the EM-31, and therefore must be considered qualitative information.

EM-31 ground conductivity data are presented in Figure 4. Areas of low conductivity are shown in blue and areas of high conductivity are shown in red. The contour interval is 5 milliSiemens per meter $(5 \mathrm{mS} / \mathrm{m})$.

Ground conductivity values vary from $15 \mathrm{mS} / \mathrm{m}$ to well over $200 \mathrm{mS} / \mathrm{m}$ near the fences. Typical background conductivity values outside the MWL are on the order of $15 \mathrm{mS} / \mathrm{m}$. Data adversely affected by the perimeter fences were removed from the data set to allow reasonable graphical presentation. As seen in Figure 4, EM-31 conductivity had no meaningful measurements closer than 15 feet to the fences, and a meaningful background level was not established. Despite this shortcoming, two significant features were observed. There is a distinct feature along grid line 155E, between $60 \mathrm{~S}$ and $100 \mathrm{~S}$, marked by high-amplitude, low-conductivity anomalies. The magnitude and limited extent of these anomalies indicates buried metal. There are also two broad areas of low conductivity centered on grid line 100E. These features may indicate areas of undisturbed ground or the burial of low density, nonconductive material.

Typical in-phase response for a well-tuned instrument in the absence of surface or subsurface metal should be on the order of a few tenths of ppt, either negative or positive. The observed in-phase response varies from $-200 \mathrm{ppt}$ to $2400 \mathrm{ppt}$, obviously influenced by both the metal fences and buried metal. The observed readings were divided by 100 in order to decrease the data range, allowing clearer data presentation and accentuation of the features of interest.

EM-31 in-phase data are presented in Figure 5. Negative in-phase data are shown in blue, positive in-phase data are shown in green through pink. Contour lines are drawn at $0,2,4,8,12,16,20$, and $24 \mathrm{ppt} / 100$. Two distinct lineaments occur along grid lines $100 \mathrm{E}$ and $155 \mathrm{E}$. There appear to be two coalescing lineaments along grid lines $20 \mathrm{E}$ and $55 \mathrm{E}$. The feature along line $155 \mathrm{E}$ is quite pronounced, with closely spaced high- and low-amplitude anomalies, indicating a significant mass of buried metal. The feature along grid line $100 \mathrm{E}$ is distinct but of less magnitude, perhaps indicating less buried metal. The coalescing linear features along grid lines $20 \mathrm{E}$ and $55 \mathrm{E}$ may represent two very closely spaced disposal trenches. 



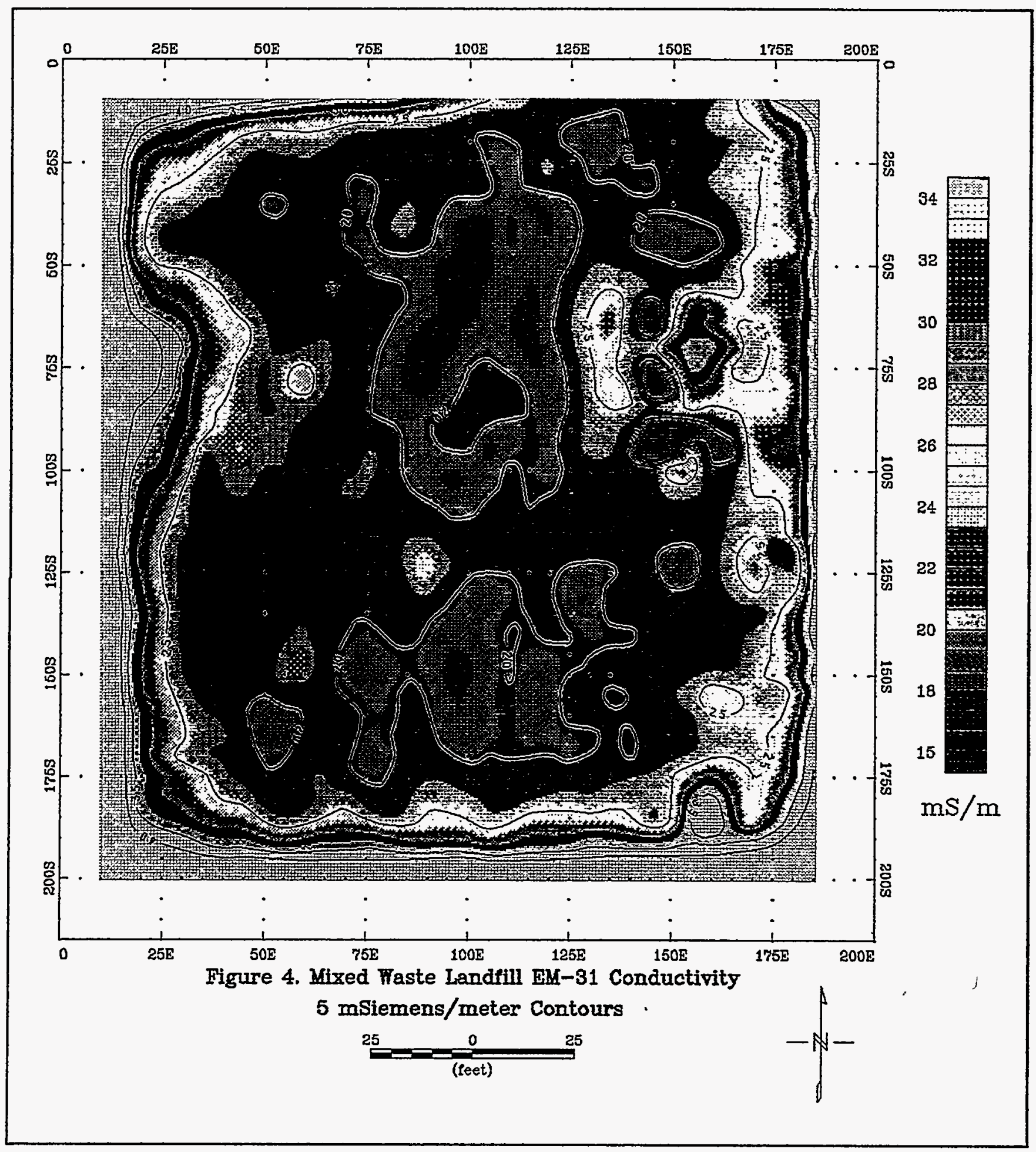





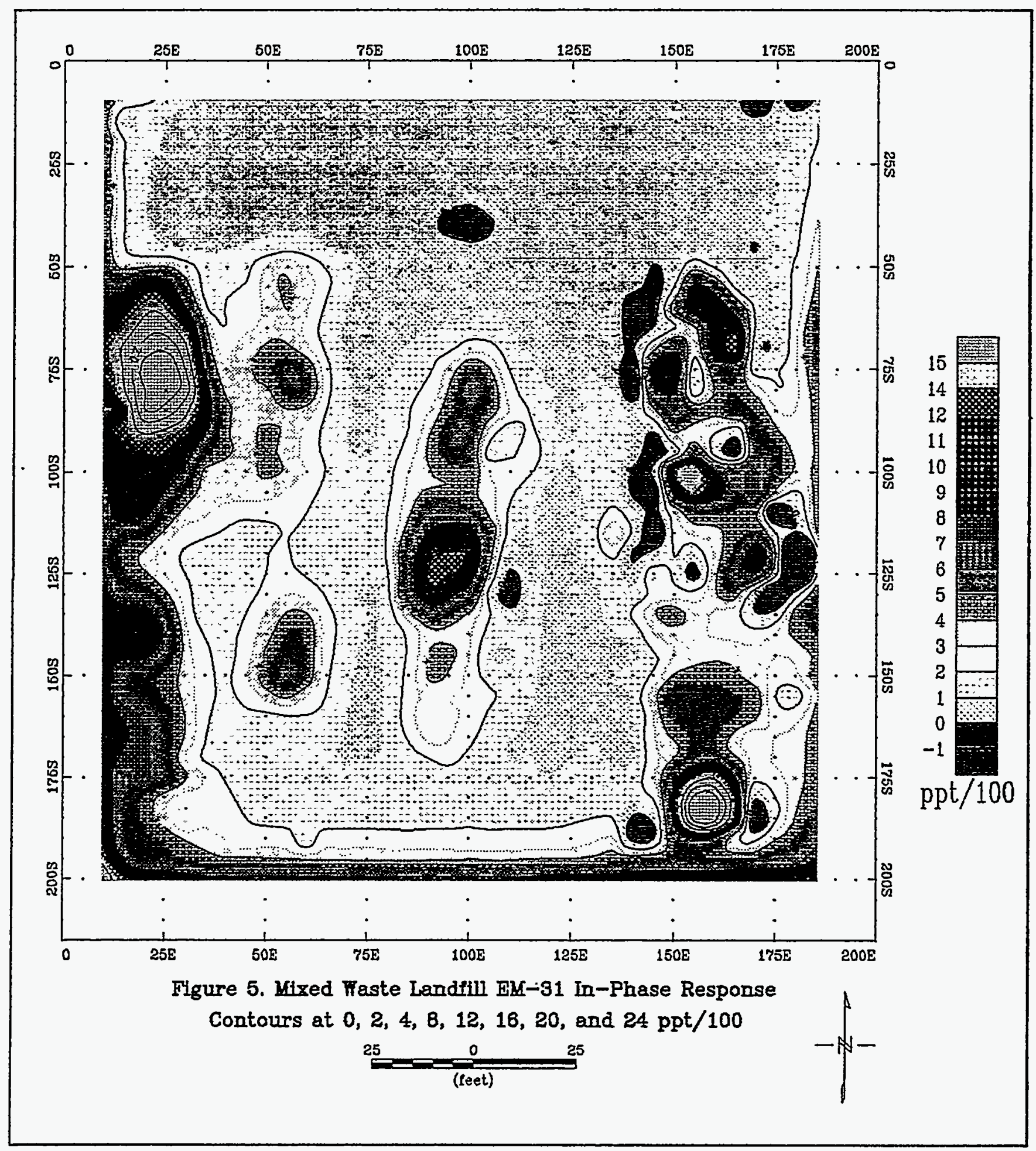




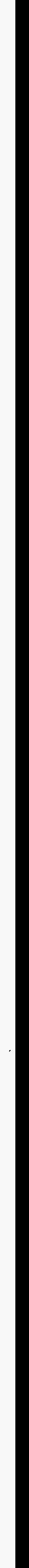




\section{Magnetic Gradient}

Total field magnetic data from the top sensor are presented in Figure 6. Magnetic highs are shown in pink and magnetic lows are shown in blue. The contour interval is $\mathbf{2 0 0}$ gamma. Bottom sensor data are presented in Figure 7. Again, magnetic highs are shown in pink and magnetic lows are shown in blue. The contour interval is 400 gamma. Vertical magnetic gradient data are presented in Figure 8. Negative gradient values trend toward blue and positive gradient values trend toward pink. The contour interval is $100 \mathrm{gamma} / \mathrm{meter}$.

Top and bottom sensor magnetic data indicate linear features along grid lines $20 \mathrm{E}$, $100 \mathrm{E}$, and $155 \mathrm{E}$. The vertical magnetic gradient data confirms these three features and an additional, more subtle linear feature, not observed in the single magnetic sensor data, along grid line 55E. Spurious dipolar anomalies are prevalent in the vertical magnetic gradient data indicating random orientation of buried ferrous objects and perhaps even remnant magnetism. At least three large metal objects or masses of ferrous material occur along grid line $155 \mathrm{E}$ at $85 \mathrm{~S}, 100 \mathrm{~S}$ and $195 \mathrm{~S}$. At least one large metal object or ferrous mass occurs along grid line $100 \mathrm{E}$, at $140 \mathrm{~S}$. One very large metal object or ferrous mass occurs along grid line $20 \mathrm{E}$ at $90 \mathrm{~S}$.

The location of the disposal trenches is quite evident when one superimposes EM-31 in-phase data and positive vertical magnetic gradient data. This superposition is presented in Figure 9. The exact outline of each trench is difficult to determine but the general location of the disposal trenches can be easily inferred to be:

Trench A: Along grid line 20E between 50S and 200S.

Trench B: Along grid line 55E between $45 \mathrm{~S}$ and $175 \mathrm{~S}$.

Trench C: Along grid line 100E between 70S and 185S.

Trench D: Along grid line 155E between 50S and 205S.

\section{Metal Detection}

EM-61 response data are presented in Figure 10. Increasing response trends toward pink. Contours are drawn at 5, 25, 50, 100, 200 and $500 \mathrm{mV}$. EM-61 response data ranges from a few $\mathrm{mV}$ (background) to several hundred $\mathrm{mV}$.

The location and outline of each disposal trench is immediately obvious. Disposal trenches occur along grid line 20E between $50 \mathrm{~S}$ and 200S; along grid line 55E between $30 \mathrm{~S}$ and $170 \mathrm{~S}$; along grid line $100 \mathrm{E}$ between $70 \mathrm{~S}$ and 180S; and along grid line $155 \mathrm{E}$ between $50 \mathrm{~S}$ and $200 \mathrm{~S}$. 



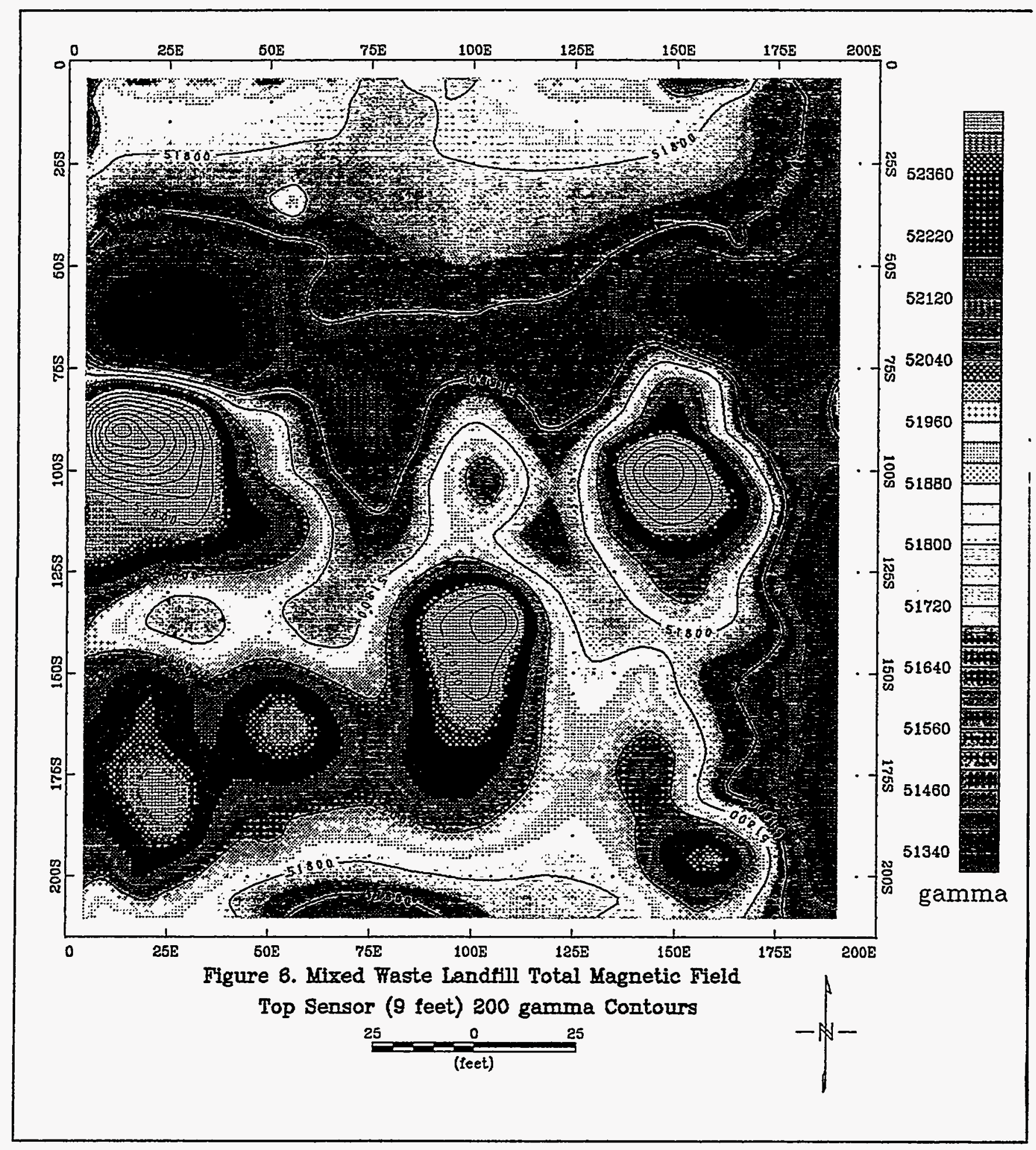





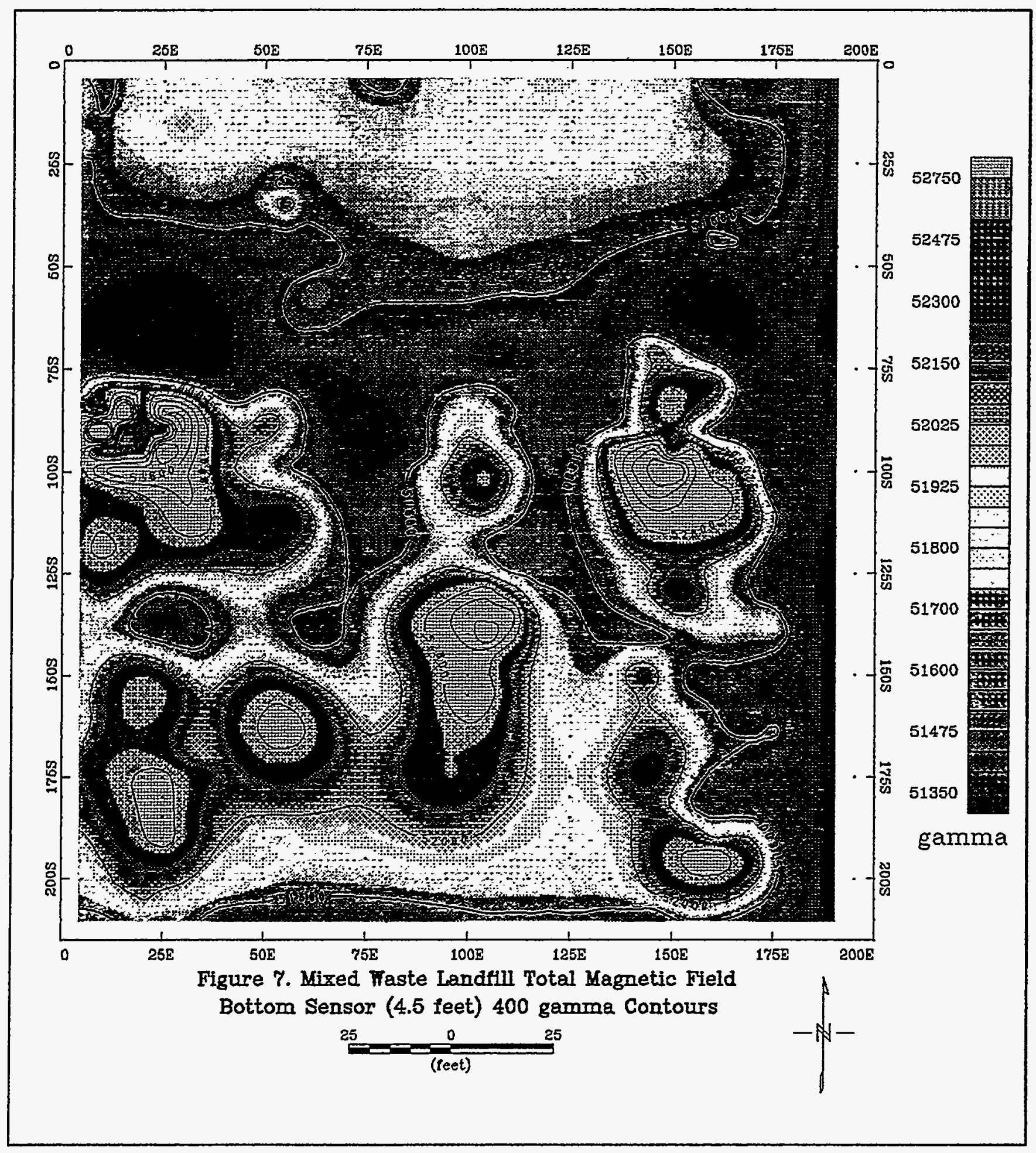




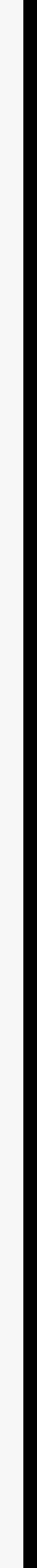




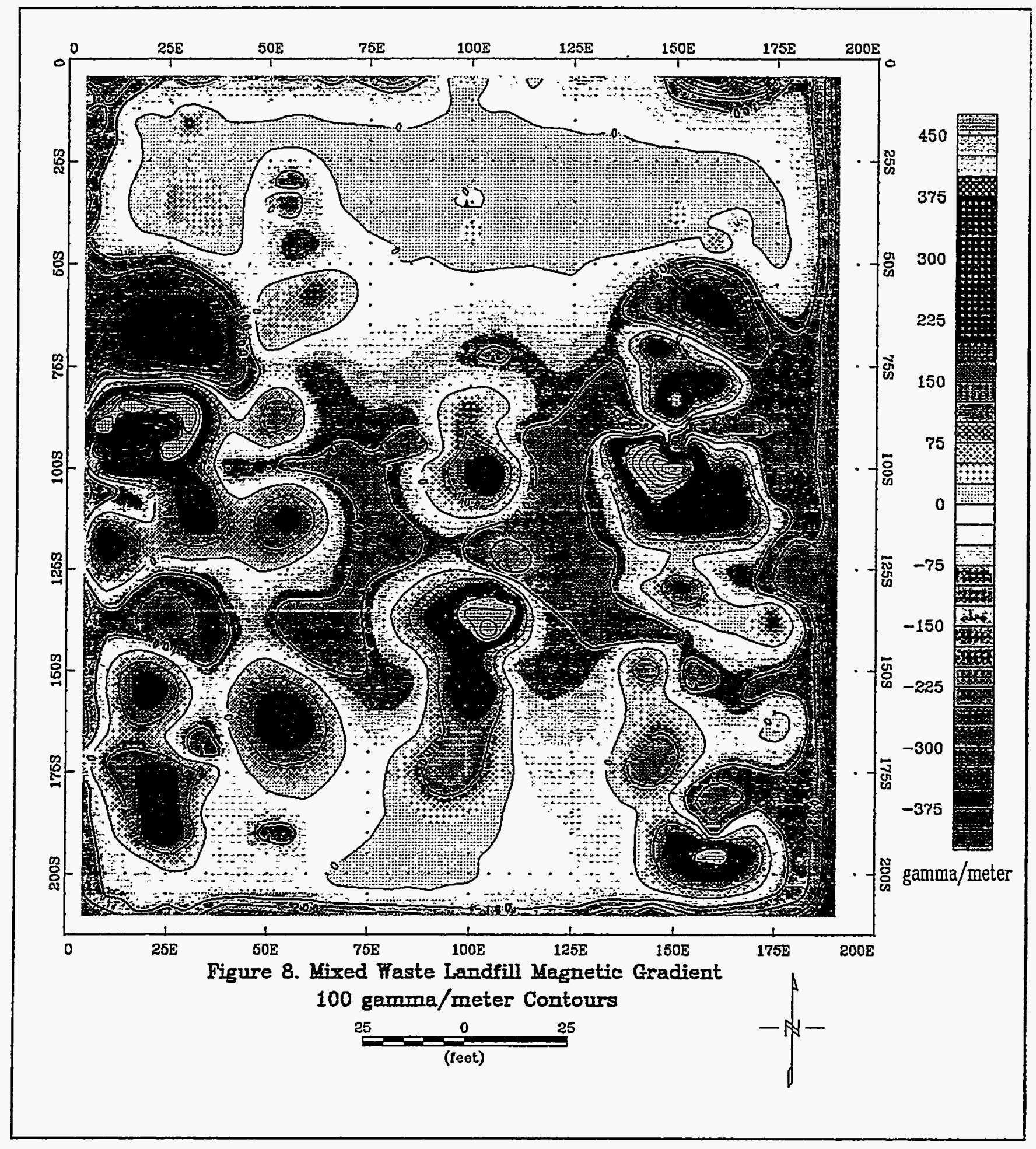











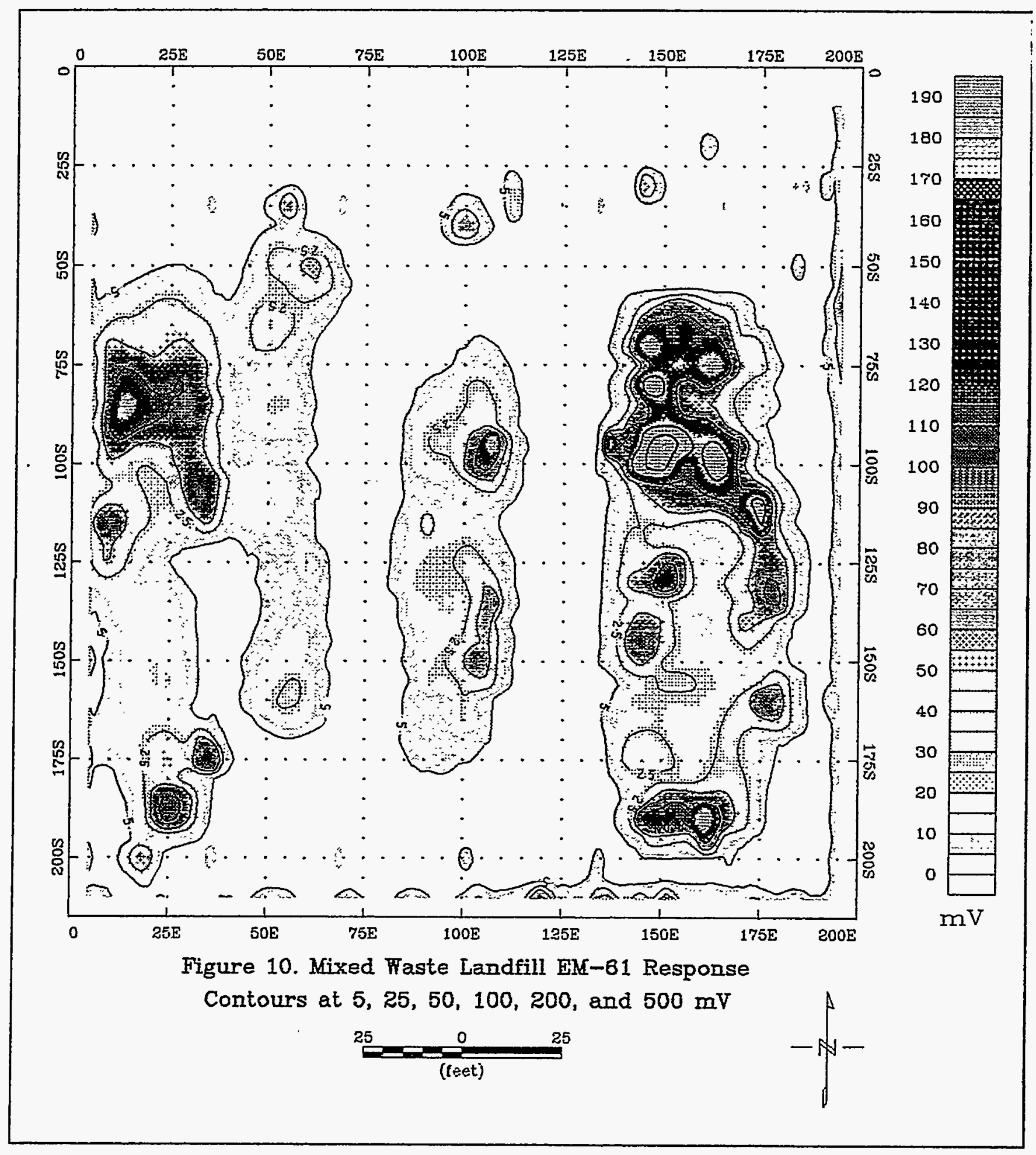





\section{Discussion and Evaluation}

The Geonics EM-61 provided the most conclusive information during this investigation. Four disposal trenches were located and clearly delineated. The "asbuilt" configuration is, as suspected, quite different from the engineered design as depicted on engineering design map 91342 (compare Figures 2 and 10). The actual disposal trenches are not of equal length, width, and spacing on the 1-acre disposal site and were not constructed with sloping walls.

The Geonics EM-31 was moderately successful in determining the location of the disposal trenches. In-phase data provided conclusive evidence that 4 disposal trenches were present, but trench dimensions were poorly defined. Conductivity data was inconclusive. This may have been due to the small survey area or the obtrusive effect of perimeter fences and metal fence posts.

The Geometrics G-856AX was successful in determining the location of the disposal trenches. Vertical magnetic gradient data provided much better resolution and sensitivity than EM-31 in-phase data, particularly to buried ferrous objects. Vertical magnetic gradient data was more definitive than EM-31 in-phase data but actual trench dimension remained poorly defined.

MWL historical records reveal that Trench A was the first trench to be excavated for waste disposal at the landfill. Excavated soils were stockpiled just east of Trench A, the designated location of Trench B. As Trench A was filled with waste, the need for another disposal trench arose. Trench $D$ was the second trench to be excavated because the location for Trench B was covered with Trench A soil. Trench D soil was stockpiled just west of Trench D, the designated location of Trench C. When Trench A was closed and backfilled with stockpiled soil, Trench B became the next available trench for excavation. Trench B was excavated while Trench D was being filled with waste. When Trench $\mathrm{D}$ was closed and backfilled, Trench $\mathrm{C}$ became the next available trench for excavation. Trench $\mathrm{C}$ was the last trench to be excavated for waste disposal in the northern half of the unclassified area of the landfill.

Trench A was probably constructed with vertical walls rather than sloped walls as specified on design map 91342. This would account for Trench A's prominent geophysical signature immediately adjacent to the western fenceline. Trench B was also probably constructed with vertical rather than sloped walls. This would account for the apparent contiguousity of Trenches A and B as indicated in the geophysical data. Construction of Trench B occurred well after Trench A had been backfilled and closed. Indeed, excavation of Trench B almost intersected Trench A! 


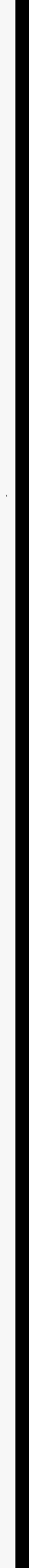


Historical records indicate that there was a fire in Trench B in 1975. This would account for Trench B's noticeably weak geophysical signature as compared to Trench $\mathrm{A}, \mathrm{C}$, and D.

Trench $\mathrm{C}$ was also probably constructed with vertical rather than sloped walls. Trench C's geophysical signature is comparable to Trench A and B's signature. Trench D, however, was probably constructed with sloped walls as originally designed. Trench D's geophysical signature is much wider than the signatures of the other trenches. Trench D is probably the only trench constructed according to the original specified design. Why construction of the trenches varied so much from trench to trench is unknown.

\section{Conclusion}

The EM-61 was the most efficient, cost-effective geophysical instrument used during this investigation. The new instrument proved to be outstanding for MWL RCRA non-intrusive assessment. The survey was completed in 4 hours by a single operator. Data was easy to interpret and response shape was simple and immediately obvious. Potentially troublesome perimeter fences had little, if any, effect on response data. Spatial resolution was excellent, even in areas with multiple buried objects, whether ferrous or non-ferrous.

The ground conductivity portion of the EM-31 survey was inconclusive. The in-phase portion, however, successfully located all 4 trenches. The vertical magnetic gradient survey successfully located all 4 trenches, confirming EM-31 in-phase data, and was particularly sensitive to buried ferrous objects. EM-31 in-phase and vertical magnetic gradient, in combination, were adequate site assessment tools but neither technique, as an independent survey, provided enough information to confidently proceed with intrusive assessment activities.

Approximately 60 man-hours were expended conducting all the geophysical surveys. This expenditure was higher than what one would expect for a comparable survey on a similar-sized site. The MWL is a Radioactive Materials Management Area which requires additional radiological support from health physics personnel. Data reduction and reporting required 16 man-hours. This incidental expenditure of resources demonstrates the efficiency and cost-effectiveness of geophysical methods, as a whole, for non-intrusive site assessment. The EM-61 distinguished itself as the instrument of choice in future ER Project waste-site assessment, particularly for locating buried metal, whether ferrous or non-ferrous. 


\section{References}

Geonics, 1992, DL720/31 Data Logging System Operating Instructions for EM31 Ground Conductivity Meter, Version 3.20

Geonics, 1994, Computer Program Manual DAT61, Version 1.31

Geosoft, 1994, Mapping and Processing System, Version 3.0

TerraSense, 1993, MAGLOC, Magnetic Data Location Program, Version 1.15 



\section{DISTRIBUTION:}

1 David A. Hyndman Sunbelt Geophysics P.O. Box 36404

Albuquerque, NM 87176

1 Lee A. Brouillard

Intera

1650 University Blvd. NE

Suite 300

Albuquerque, NM 87102

1 MS 1309 Environmental Operations Records Center, 7512

1 . MS 1147 W. B. Cox, 7581

$1 \quad$ MS 1148 R. E. Fate, 7585

1 MS 1148 J. L. Peace, 7585

1 MS 1148 T. J. Goering, 7585

1 MS 1148 M. D. McVey, 7585

2 MS 0100 Document Processing, 7613-2 For DOE/OSTI

1 MS 1093 W. G. Rhodes, 7713

$1 \quad$ MS 1093 H. D. Oldewage, 7714-3

1 MS 9018 Central Technical Files, 8523-2

1 MS 0619 Print Media, 12615

5 MS 0899 Technical Library, 13414 
